\title{
Mechanical and Electrical Performance of Thermally Stable Au-ZnO films
}

\author{
R. L. Schoeppner ${ }^{\mathrm{a}}$, R. S. Goeke ${ }^{\mathrm{b}}$, N. R. Moody ${ }^{\mathrm{c}}$, D. F. Bahr ${ }^{\mathrm{d}}$ \\ ${ }^{a}$ Washington State University, Material Science and Engineering Program, Pullman, WA 99163 USA \\ ${ }^{\mathrm{b}}$ Sandia National Laboratory, Albuquerque, NM 87123 USA \\ ${ }^{\mathrm{c}}$ Sandia National Laboratory, Livermore, CA 94588 USA \\ ${ }^{\mathrm{d}}$ Purdue University, Materials Engineering, West Lafayette, IN 47907 USA
}

\begin{abstract}
The mechanical properties, thermal stability, and electrical performance of $\mathrm{Au}-\mathrm{ZnO}$ composite thin films are determined in this work. The co-deposition of $\mathrm{ZnO}$ with $\mathrm{Au}$ via physical vapor deposition leads to grain refinement over that of pure $\mathrm{Au}$; the addition of 0.1 vol\% $\mathrm{ZnO}$ reduces the as-grown grain size by over $30 \%$. The hardness of the as-grown films doubles with $2 \% \mathrm{ZnO}$, from 1.8 to $3.6 \mathrm{GPa}$ as measured by nanoindentation. Films with $\mathrm{ZnO}$ additions greater than $0.5 \%$ show no significant grain growth after annealing at $350^{\circ} \mathrm{C}$, while pure gold and smaller additions do exhibit grain growth and subsequent mechanical softening. Films with $1 \%$ and $2 \% \mathrm{ZnO}$ show a decrease of approximately $50 \%$ in electrical resistivity and no change in hardness after annealing. A model accounting for both changes in the interface structure between dispersed $\mathrm{ZnO}$ particles and the $\mathrm{Au}$ matrix captures the changes in mechanical and electrical resistivity. The addition 1-2\% $\mathrm{ZnO}$ co-deposited with Au provides a method to create mechanically hard and thermally stable films with a resistivity less than $80 \mathrm{n} \Omega-\mathrm{m}$. These results complement previous studies of other alloying systems, suggesting oxide dispersion strengthened (ODS) gold shows a desirable hardness-resistivity relationship that is relatively independent of the particular ODS chemistry.
\end{abstract}

Keywords: Oxide Dispersion Strengthening, Annealing, Electrical Resistivity, Nanoindentation Corresponding Author: David F. Bahr, dfbahr@purdue.edu P: (765)494-4100 F: (765)494-1204 


\section{Introduction}

Electrical contacts can undergo numerous loading cycles in the course of their effective life, which can cause considerable degradation of the mechanical and electrical properties from grain growth [1-5] and micro-welding [6-8]. Traditionally gold is used for electrical contacts due to its high electrical conductivity and resistance to corrosion, oxidation and other environmental effects. However, pure gold is a low strength material that often is not able to withstand substantial contact loading. Additionally, high currents passed through the switch can lead to micro-welding from Joule heating, followed by detrimental deformation when the contact is broken $[9,10]$. In order to increase the lifetime of these contacts, numerous different techniques are used to increase the wear resistance by increasing the hardness of Au: grain size reduction [11-14], addition of solid solution impurities [3,13,15-17], deposition of nanolaminate structures [18-20], or the introduction of small oxide particles [15,21,22]. However, all of these strengthening techniques can substantially increase the resistivity of $\mathrm{Au}$.

One of the most common ways to increase the strength of a material is to reduce the grain size. However, many materials with very fine grain sizes have shown evidence of stress-induced grain growth, which leads to a decrease in strength. Studies conducted on nanocrystalline materials [21-22] suggest this type of grain growth can be attributed to grain-boundary sliding, diffusion, and grain rotation; therefore, if these are reduced, grain growth should be slowed or even stopped. Impurities introduced into the system can stabilize nanocrystalline microstructures by reducing grain boundary mobility and thereby stopping grain growth [17,25-27]. Therefore, solid-solution strengthening, [13,28,29], could also potentially reduce stress-induced grain growth. In these types of systems, strength increases with the square root of impurity 
concentration, but is highly dependent on the type of impurity and its solubility in the host material [30,31].

Another way to increase the strength of gold films is via oxide dispersion strengthening (ODS), where small oxide particles act as precipitates to block dislocation motion [30]. One aspect of the ODS technique that shows great promise is the ability to increase hardness without greatly affecting conductivity [21]. ODS Au with $\mathrm{V}, \mathrm{Au}-\mathrm{V}_{2} \mathrm{O}_{5}$, showed both a larger increase in hardness coupled with a smaller increase in resistivity as a function of V content when compared to a Au-V solid-solution. This suggests that the ODS films are more effective in strengthening a film when high conductivity is still desired, which should lead to increased wear resistance, grain boundary pinning, and a comparatively smaller reduction in electrical conductivity.

The drawback to adding any impurities to pure materials is the disruption of the electrical pathway. All three strengthening mechanisms (grain size reduction, solid-solution strengthening, and oxide dispersion strengthening) lead to an increase in resistivity by the same general mechanism, electron scattering at the defect site [32,33]. Electrical conductivity in metals relates directly to the mean free path, $\lambda$, of the electron. For the case of grain boundary scattering in very small grains, $\lambda$ is approximately equal to the size of the grain; therefore, small-grained materials have higher resistivity. Similarly, a disruption in the regular crystal structure of the metal leads to local strain fields that also disrupt the path of electrons, causing the resistivity to increase. This is seen in both solid solution and precipitation strengthened metals. The study conducted by Bannuru et. al on $\mathrm{Au}-\mathrm{V}$ and $\mathrm{Au}-\mathrm{V}_{2} \mathrm{O}_{5}$ show that the solid-solution $\mathrm{Au}-\mathrm{V}$ has an electrical resisitivity four times that of the ODS film with the same V content, suggesting solid-solution atoms can cause more electron scattering than an ODS material with the same volume percentage [21]. Additional causes of increased resistivity include temperature, vacancies, and dislocations. 
Since resistivity is an additive property [32], a combination of different types of strengthening mechanisms will continuously increase the resistivity of the material. The ODS system used in this investigation has been shown in previous studies to lead to a reduced grain size over pure gold films as well as particle strengthening when compared to a pure Au film [34], leading to scattering from both grain boundaries as well as oxide particles.

\section{Experimental Details}

$\mathrm{Au}-\mathrm{ZnO}$ ODS thin films were deposited on single crystal silicon wafers $\left(t_{s}=550 \mu \mathrm{m}\right.$ and biaxial elastic modulus, $M=180.5 \mathrm{GPa}$ ) using dual source e-beam evaporation to a thickness of approximately $2 \mu \mathrm{m}$ as was previously described by Argibay and coworkers [35]. Titanium and platinum ( $250 \mathrm{~nm}$ each) were used as adhesion/diffusion barrier layers between the film and $\mathrm{Si}$ substrate. Four concentrations were investigated in this study: 0.1, 0.5, 1.0 and $2.0 \mathrm{vol} \% \mathrm{ZnO}$ and compared to pure Au deposited under the same conditions. XRD data were collected with a PANalytical Empyrean X-ray diffractometer equipped with a PIXcel ${ }^{3 \mathrm{D}}$ detector and operated at $45 \mathrm{kV}$ and $40 \mathrm{kA}$ using $\mathrm{Cu} K \alpha$ radiation $(\lambda=1.5418 \AA$ ). The patterns were collected in the $2 \theta$ range of 10 to $90^{\circ}$, with a step size of $0.026^{\circ}$, and exposure time of 300 seconds. Diffraction pattern processing was performed using the software package HighScore Plus ${ }^{\circledR}$. Rietveld refinement analysis of the patterns show lattice compressive percent strains to be $0.00,0.081$, $0.052,0.065$, and 0.058 for pure $\mathrm{Au}, 0.1 \% \mathrm{ZnO}, 0.5 \% \mathrm{ZnO}, 1.0 \% \mathrm{ZnO}$, and $2.0 \% \mathrm{ZnO}$ respectively.

Wafer curvature experiments were conducted on a custom machine designed and built at the Erich Schmidt Institute in Leoben, Austria. The wafer curvature chamber was put under vacuum and allowed to come to pressure for at least 20 minutes, which results in a base pressure 
of approximately $10^{-4}-10^{-5}$ Torr. Initial curvature readings were taken at room temperature $\left(25^{\circ} \mathrm{C}\right)$, and the stresses calculated from curvature results were offset by the initial internal stress calculated from lattice strain measurements determined by the Rietveld refinement of the XRD scans. Each sample was cycled up to a temperature of $350^{\circ} \mathrm{C}$ and back to room temperature at a rate of $0.17^{\circ} \mathrm{C} / \mathrm{s}$ for one cycle, after which electron backscatter diffraction (EBSD) using a Zeiss SEM (LEO 1525) system was conducted to determine microstructural changes. To determine the stability of the microstructure, three concentrations (pure $\mathrm{Au}, 0.5 \% \mathrm{ZnO}$, and $2.0 \% \mathrm{ZnO}$ ) were then cycled an additional four times and examined once again using EBSD. All changes in microstructure due to annealing were determined using EBSD with an accelerating voltage of 20 $\mathrm{kV}$, and scan resolution of $0.02 \mu \mathrm{m} /$ point and analyzed using TSL OIM Analysis 5 software. Confidence index standardization was utilized in determining grain size and orientation.

Nanoindentation with a Hysitron TI 950 Triboindenter was performed on as-deposited and annealed samples using a Berkovich diamond tip at a constant load of $1250 \mu \mathrm{N}$ and loading rate of $200 \mu \mathrm{N} / \mathrm{s}$ with a hold segment of 30 seconds to reduce effects of creep. Fifteen indents were performed at a spacing of $15 \mu \mathrm{m}$. Four-point probe resistance measurements were conducted before and after annealing using a Jandel multi height, inline probe with a probe spacing of 1 $\mathrm{mm}$. A $10 \mathrm{mV}$ voltage was applied to the outer probes and the resulting current recorded from at least 3 different measurements. The resulting resistivity values were calculated using thickness measurements determined from cross sections in a scanning electron microscope and using a geometry modified sheet resistance to account for edge effects due to the small sample size [36]. 


\section{Results}

\subsection{Wafer Curvature}

Wafer curvature experiments were conducted on each of the films to determine the stability of this ODS system under high stress and temperature conditions. The films were cycled under the delamination temperature $\left(\approx 400{ }^{\circ} \mathrm{C}\right)$, insuring that any plasticity is a result of microstructural changes or typical yielding expected in metallic films and not a result of delamination or buckling. Stress-temperature curves were calculated from wafer curvature using:

$$
\sigma_{f}=\frac{E_{s} t_{s}{ }^{2}}{6(1-v) t_{f} R}
$$

where $E_{s}$ is the substrate biaxial modulus, $t_{s}$ is the substrate thickness, $v$ is the film Poisson's ratio, $t_{f}$ the film thickness, and $R$ is the measured curvature. The exact substrate and film thickness for each sample was determined using cross sections in the SEM.

Stress-temperature results from the first $350^{\circ} \mathrm{C}$ wafer curvature cycles are shown in Figure 1a. The initial stress and curvature was fixed at the value from the as-deposited stress measurements calculated from XRD lattice strain measurements, summarized in Table 1. The heating segment of all the curves follow approximately the same slope ( $\left.M_{\text {heating }}\right)$ until initial yielding, indicating the elastic modulus is independent of $\mathrm{ZnO}$ concentration as would be expected in these dilute solutions. After the initial elastic portion of the heating curve, the stress slowly levels out as the temperature increases, indicating the start of plasticity brought on by diffusion-based creep, dislocation motion, grain growth, or phase transformations [37-39], most likely a mixture of multiple mechanisms depending on the stress and temperature state [40-42]. The stress at the onset of plasticity $\left(\sigma_{\min }\right)$ is unique for each film and is indicative of the strength of the film, with increasing strength for increasing $\mathrm{ZnO}$ content. As the temperature increases it 
is easier to activate thermally controlled deformation processes; therefore, the onset of plasticity is a coupled stress-temperature response with stronger films yielding at both higher stresses as well as higher temperatures. However, since the yield strength is a temperature sensitive property these strengths cannot be directly compared to the room temperature nanoindentation results. After the onset of plasticity, all of the films undergo a similar stress reduction $\left(\Delta \sigma_{\mathrm{p}}\right)$ (within $\left.5 \%\right)$ indicating the same deformation mechanisms are active in all systems and independent of $\mathrm{ZnO}$ concentration. The initial portion of the cooling curve depicts elastic deformation and therefore, the stress rises at approximately the same rate regardless of $\mathrm{ZnO}$ concentration as was seen in the heating portion of the curves. As the temperature drops further, the slopes $\left(M_{\text {cooling }}(P)\right)$ begin to deviate with $\mathrm{Au}, 0.1 \% \mathrm{ZnO}$ and $0.5 \% \mathrm{ZnO}$ following similar paths and $1.0 \%$ and $2.0 \% \mathrm{ZnO}$ following another. The change in the cooling profile suggests a change in the microstructure of the film is occurring. Specifically, if significant grain growth occurred in the $\mathrm{Au}, 0.1 \% \mathrm{ZnO}$, and $0.5 \% \mathrm{ZnO}$ films, the strength and strain-hardening ability would be reduced, leading to a shallower slope. Table 2 summarizes the differences between all the five curves, with specific changes in bold.

Three of the films were thermally cycled an additional four times to determine the stability of the microstructure. Pure $\mathrm{Au}, 0.5 \% \mathrm{ZnO}$, and $2.0 \% \mathrm{ZnO}$ were chosen since these three concentrations showed characteristics of all films, with $0.1 \% \mathrm{ZnO}$ and $1.0 \% \mathrm{ZnO}$ performing similarly to pure $\mathrm{Au}$ and $2.0 \% \mathrm{ZnO}$, respectively. Stress-temperature curves were offset so that the starting stress in the films is the same as the ending stress from the first cycle, with the assumption that limited stress relaxation would occur in the films at room temperature. Figure $1 \mathrm{~b}$ shows the stress-temperature response from multiple thermal cycles to $350^{\circ} \mathrm{C}$. Pure $\mathrm{Au}$ undergoes one additional $60 \mathrm{MPa}$ increase in tensile stress after the second cycle, however, the 
overlapping loops seen in the last three cycles indicates a stable microstructure. The $0.5 \% \mathrm{ZnO}$ film also undergoes an additional $60 \mathrm{MPa}$ stress increase after the second cycle; however, this film continues to raster after each additional cycle suggesting continued grain growth. This evolving stress-temperature profile suggests that the microstructure is also evolving with each additional cycle. The $2.0 \% \mathrm{ZnO}$ exhibits effectively an elastic response through the entire temperature regime, with each additional cycle overlapped on the previous one, indicating a stable microstructure.

\subsection{Microstructural Evolution}

To examine microstructural changes as a result of the wafer curvature experiment, EBSD was used to investigate the grain size distribution and texture of the films in their as-deposited condition and after thermal cycling (Figure 2). The starting microstructure for each film (top row) shows predominantly (111) textured, nanocrystalline grains; however as $\mathrm{ZnO}$ particles are introduced into the system, both the texture strength and grain size decrease significantly with grain size reducing by $35 \%$ and texture strength dropping by $40-70 \%$ (not shown in the figure). After one thermal cycle to $350^{\circ} \mathrm{C}$ (bottom row), grain growth is seen for the pure $\mathrm{Au}$ and $0.1 \% \mathrm{ZnO}$, with grain sizes increasing by over an order of magnitude. Additionally, both films develop a significant number of annealing twins, doubling the number of $\Sigma 3$ boundaries. The $0.5 \% \mathrm{ZnO}$ sample develops a bimodal distribution with approximately $60 \%$ of the original nanocrystalline grains along with a few larger grains that also show signs of twinning. Twinning as a mode of strain reduction is commonly found in materials with low stacking fault energy [43,44] with the potential to compensate for up to $16.7 \%$ in-plane strain by creating a set of orthogonal twins [44]. This twinning mechanism could provide one explanation for the change in 
cooling slope seen in the pure $\mathrm{Au}, 0.1 \% \mathrm{ZnO}$, and $0.5 \% \mathrm{ZnO}$ stress-temperature curves. Both $1.0 \% \mathrm{ZnO}$ and $2.0 \% \mathrm{ZnO}$ show little to no grain growth as a result of this particular annealing condition.

After repetitive cycling of the pure $\mathrm{Au}, 0.5 \% \mathrm{ZnO}$, and $2.0 \% \mathrm{ZnO}$ film, the microstructures were once again examined using EBSD to determine microstructural stability through multiple temperature cycles. Figure 3 highlights the evolution of the grain size distribution from the as-deposited condition (solid line), after undergoing one thermal cycle (dashed line), and after five thermal cycles (dotted line) for pure $\mathrm{Au}, 0.5 \% \mathrm{ZnO}$, and $2.0 \% \mathrm{ZnO}$. Pure Au shows an order of magnitude increase in grain size after only one thermal cycle, but only a very slight additional increase after five thermal cycles, indicating grain growth is essentially complete after the initial $350^{\circ} \mathrm{C}$ anneal. After the first cycle of the $0.5 \% \mathrm{ZnO}$ film, an obvious bimodal distribution develops consisting of one mode with the original grain size and the second mode with diameters approximately 10 times larger (with approximately a 3:1 ratio of small grains to large grains). However, there is additional grain growth during the five thermal cycles where the fraction of small grains is drastically reduced and the ratio of small grains to larger grains is closer to $1: 1$. This continually evolving grain size indicates that this concentration of $\mathrm{ZnO}$ is not sufficient to completely pin the grain boundaries. Finally, there is virtually no change in grain size distribution for the $2.0 \% \mathrm{ZnO}$ films regardless of the number of cycles in this study, which shows a concentration of $2.0 \mathrm{vol} \% \mathrm{ZnO}$ is enough to successfully pin the grain boundaries to stop grain growth. Therefore, it is apparent that there is a minimum concentration of $\mathrm{ZnO}$ required in the nanocomposite to successfully prohibit grain growth, somewhere between $0.5 \% \mathrm{ZnO}$ and $2.0 \% \mathrm{ZnO}$. 


\subsection{Mechanical and Electrical Response of As-Deposited and Annealed Films}

\subsubsection{Annealing Effect on Hardness}

Nanoindentation of both the as-deposited and annealed conditions (Figure 4) was conducted to determine the change in hardness as a result of $\mathrm{ZnO}$ concentration and their reaction to a coupled stress-thermal cycling. As-deposited films show a non-linear increase in hardness with the addition of $\mathrm{ZnO}$ particles likely due to a combination of strengthening methods. The hardness increase due to increasing additions of $\mathrm{ZnO}$ particles scales similarly to that previously shown by Argibay et. al. [35], with an increase of about $1.8 \mathrm{GPa}$ from pure Au to 2.0\% ZnO. Overall magnitude differences between this study and that previous work on similar films are likely attributable to the indentation size effect (ISE), with tests in the current study being at depths significantly smaller than the previous work. The nanocomposite films show asdeposited grain sizes approximately 35\% smaller than pure Au (see Figure 2), which would result in an increased hardness strictly a result of the smaller grain structure [12,14]. The remaining increase in hardness is likely due to oxide particle strengthening which can be modeled according to the Ashby-Orowan model [30] and follows a $\approx-1 / 3$ power law relationship with volume fraction [45].

Previous energy dispersive spectroscopy (EDS) scans conducted on 5.0\% ZnO films show approximately $20 \%$ of the $\mathrm{Zn}$ deposits at the grain boundaries, with the remaining dispersed throughout the grains. Assuming the percentage of $\mathrm{ZnO}$ deposited at the grain boundaries is consistent for low concentration nanocomposites, the volume fraction of $\mathrm{ZnO}$ available for particle strengthening, $x$, is actually $0.8 f$. Combining Hall-Petch and hard precipitate strengthening with the base strength of pure Au leads to a combined hardness model such that: 


$$
H_{A u-Z n O}=2.7\left[\sigma_{o}+K_{H P}\left(d_{A u-Z n O}^{-\frac{1}{2}}\right)+2 \frac{G b}{2 \pi L} \ln \frac{2 r}{2 b}\right]
$$

where $\sigma_{o}$ is a combination of the stress required to move a dislocation in the Au lattice and the ISE, $K_{H P}$ is the grain boundary strengthening coefficient, $d$ is grain diameter, $G$ is the shear modulus, $b$ is the burgers vector, $L$ is the surface to surface particle spacing, and $r$ is the average particle radius (between 2-5 nm for this work based on preliminary TEM studies). The conversion between uniaxial strength and hardness uses the well-established Tabor factor of 2.7.

The combined stress and ISE parameter, $\sigma_{o}$, is assumed to be independent of concentration and is used as a fitting parameter when minimizing the combined least squares model. The grain-boundary strengthening component was calculated using the grain size distributions from the EBSD scans rather than strictly using the average grain size to incorporate the wide and bimodal distributions found in annealed films. Using OIM software, area fractions of grain diameters were determined using 20 bins, included twins but excluded edge grains. The resulting hardness contribution from Hall-Petch strengthening was then calculated according to the relationship:

$$
H_{H-P}=2.7 K_{H P} \sum a_{f}\left(d_{A u-Z n O}^{-\frac{1}{2}}\right)
$$

where $a_{f}$ is the area fraction of grains with grain diameter, $d$. A study conducted by Emery $[46,47]$ on thin, small grained Au films showed a deviation from Hall-Petch behavior at grain sizes lower than $790 \mathrm{~nm}$, with a strengthening coefficient lower than that observed in coarse grain films. Therefore, grains that are larger than $790 \mathrm{~nm}$ have a $K_{H P}=7.9 \mathrm{GPa}^{*} \mathrm{~nm}^{1 / 2}$ while the coefficient for grains smaller than $790 \mathrm{~nm}$ was $K_{H P}=5.13$. Figure 5 shows the contribution from each parameter according to the least squares fit for the combined as-deposited and annealed 
model with a particle diameter of $4.1 \mathrm{~nm}$, when grain size is below $790 \mathrm{~nm}$ and $\sigma_{o}=223 \mathrm{MPa}$. Very good agreement is seen between the model and experimental results for both the asdeposited and annealed conditions. The only strengthening mechanism which changes significantly as a result of annealing is the Hall-Petch component, suggesting there is no change in $\mathrm{ZnO}$ particle spacing or a migration of $\mathrm{Zn}$ in solution to the grain boundaries, which can readily occur in solid-solution strengthened materials.

\subsubsection{Annealing Effect on Resistivity}

Electrical changes as a result of annealing were investigated using the four-point probe technique to determine sheet resistance of the films (Figure 6). Due to the presence of the Ti/Pt adhesion layers, the resistivity values determined in this study are slightly different than those previously reported for similar films [48]; however, the relative resistivity (when normalized by pure $\mathrm{Au}$ ) is comparable. Resistivity was calculated based on individual film thicknesses (verified from SEM cross-sectional measurements) and the geometric correction for sample size [36,49]. As-deposited resistivity of these $\mathrm{Au}-\mathrm{ZnO}$ films follow an expected trend where increasing $\mathrm{ZnO}$ concentration creates increasing resistance in the film due to a larger amount of scattering from interactions with particles. However, the resistivity of the annealed films shows two differing phenomenon; pure $\mathrm{Au}$ and $0.1 \% \mathrm{ZnO}$ films increase in resistivity following grain growth while the higher concentration ODS films exhibit a decrease in resistivity without showing any obvious change in microstructure.

Internal stresses can lead to electron scattering and an increase in resistivity [50,51], which could be one reason for the slight increase in resistivity in the annealed films of pure Au and $0.1 \% \mathrm{ZnO}$ in spite of the increased grain size. Annealing a thin film on a substrate can lead 
to the development of both plastic deformation and higher residual stresses in the film if annealing causes the film to be deformed beyond the elastic regime (as is the case in this annealing study). However, this explanation does not explain the drop in resistivity seen in the higher concentration films. Since traditional methods of second phase interactions on the resistivity of a material are merely dependent on the volume fraction of the second phase and have no relationship to particle spacing, they can lead to grossly inaccurate representations of resistivity due to composites with a fine dispersion of small particles. Therefore, the model used in this study treats fine particles as solid solution atoms, assuming a random dispersion. Since the stress field around $\mathrm{ZnO}$ particles would lead to electron scattering and affect the resistivity in a similar way as solid-solution atoms, the same basic relationship is assumed for these ODS films where the scattering coefficient is dependent on the interface structure. A resistivity model incorporating thermal vibrations [32], grain boundary scattering [52], scattering due to internal stresses [50], and interactions with $\mathrm{ZnO}$ particles [32] was developed resulting in a general equation for an ODS Au film:

$$
\begin{gathered}
\rho_{A u-Z n O}=\rho_{A u}\left[1+\alpha_{o}(T-273)\right]\left(3\left[\frac{1}{3}-\frac{1}{2} \alpha+\alpha^{2}-\alpha^{3} \ln \left(1+\frac{1}{\alpha}\right)\right]\right)^{-1}+C_{Z n o}[x(1-x)]+C_{\sigma}\left(\sigma_{a n n}\right) \\
\alpha=\frac{\lambda}{d}\left(\frac{R}{1-R}\right)
\end{gathered}
$$

Where $\lambda$ is the mean free path of the electrons ( $44 \mathrm{~nm}$ at $298 \mathrm{~K}$ [35]), $d$ is the grain diameter according to EBSD scans, $R$ is the probability of reflection at a grain boundary, $x$ is the volume fraction of deposited $\mathrm{Zn}$ in the grains, and $C_{\mathrm{ZnO}}$ is the scattering coefficient due to $\mathrm{ZnO}$ particles in the matrix. The grain boundary scattering contribution was calculated based on a similar area fraction approach as was used to calculate the Hall-Petch strengthening component (Section 1.5.1). However, since twin boundaries are an ordered boundary and would not 
contribute to much electrical scattering [53], they are removed from grain size calculations. As was noted earlier, approximately $20 \%$ of $\mathrm{Zn}$ deposited at the grain boundaries during growth, therefore it is assumed that the probability of reflection at the grain boundaries in the higher $\mathrm{ZnO}$ containing films would be larger. Since previous investigations on resistivity in nanocrystalline Au films shows $R$ values ranging from $0.35-0.47$, a linear relationship for $R$ is assumed, ranging from $0.35-0.43$, depending on the $\mathrm{ZnO}$ concentration. $C_{\mathrm{ZnO}}$ (before and after annealing) and $C_{\sigma}$ are used as fitting parameters since the relationship due to these contributions are unknown. Figure 7 shows a summary of the calculated film resistivity components determined from the best fit of this model, and the comparison to experimental values.

\section{Discussion}

The current study shows there is a minimum concentration of $\mathrm{ZnO}$ required to successfully inhibit grain growth due to coupled stress-temperature conditions, summarized in Figure 8. Due to the gradual increase in grain size for $0.5 \% \mathrm{ZnO}$ and the stable microstructure seen in $2.0 \% \mathrm{ZnO}$, this threshold is around $1 \% \mathrm{ZnO}$. Since stress-induced grain growth is typically due to grain rotation, grain boundary sliding, and diffusion, $\mathrm{ZnO}$ particles found at the grain boundaries is likely decreasing these terms. The model describing the experimental hardness measurements of annealed films attributes most of the strength change after annealing to changes in grain size, suggesting there is no change in particle spacing due to Oswald ripening or diffusion to the grain boundaries. Therefore, the most likely cause of the change in resistivity due to annealing is a change in the interaction of the $\mathrm{ZnO}$ particles with the Au matrix. If the interface between $\mathrm{ZnO}$ particles and the $\mathrm{Au}$ matrix start off as semi-coherent, similar to those seen in Guinier-Preston zones [54] in solid-solution strengthened metals, there would be a 
significant local strain field around the particles which could lead to electron scattering. As the films undergo a stress-temperature annealing cycle, dislocations can move to relieve the strain caused by the semi-coherent interface, changing it to an incoherent interface which has a much lower strain field and would lead to less electron scattering, thus reducing the resistivity of the film. The concentration of $\mathrm{ZnO}$ would influence this behavior if the changes in electrical scattering were similar per particle. Additionally, the switch from semi-coherent to fully incoherent interface around the particles would not result in a drastic change in particle strengthening, since particle size and spacing is constant which is also seen in these results.

Williams et. al. observed a similar decrease in resistivity as a result of annealing in zirconia strengthened Au films [55]; this resistance change occurred without a significant change in grain size and was ascribed to a reduction in point defects in the lattice. The $\mathrm{Au}-\mathrm{ZrO}_{2}$ system showed a decrease in hardness with annealing, which could also be attributed to decrease in point defects within the Au lattice. The Au- $\mathrm{ZnO}$ results presented in this current suggest the presence of nm-size oxide particles stabilize the microstructure and grain size during annealing and that this phenomena is relatively independent of oxide chemistry. The presence of significant point defects in the film should be related to the film growth parameters, and therefore if the films had few point defects to begin with it is possible that there would be no significant change in hardness after annealing, as is the case in our current study of $\mathrm{Au}-\mathrm{ZnO}$.

Comparing the current results to that of other ODS Au films [21,35,55] show substantial similarities in both total magnitude as well as general trends when comparing the impact of volume fraction of oxide particles dispersed in Au for both hardness and electrical resistivity. Although the suite of these studies used different deposition techniques (reactive physical vapor deposition [21,55] and e-beam evaporation [35]), leading to slightly different microstructures, 
the overall trend of substantially increasing hardness while only slightly increasing resistivity remains the same. Both the change in resistivity and hardness as a function of volume fraction of oxide, and the magnitude of both resistivity and hardness in all four of these studies are within a factor of two (and in several cases much closer), suggesting the strengthening-resistivity relationship is relatively insensitive to the particular oxide chemistry and more dominated by the structural features of the mechanism.

Figure 8 shows a summary of the changes in both hardness and resistivity as a result of the present annealing study. Increasing $\mathrm{ZnO}$ concentrations provide a more stable microstructure that retains strengthening benefits while maintaining high conductivity. The decreasing resistivity as a result of annealing also corresponds to similar results in other ODS Au systems.

\section{Conclusions}

Stress-temperature wafer curvature experiments conducted on $\mathrm{Au}-\mathrm{ZnO}$ thin films show increasing yield strength with increasing $\mathrm{ZnO}$ concentration. A change in the stress-temperature cooling profile is caused by a change in the microstructure. There is an order of magnitude increase in grain size for pure $\mathrm{Au}$ and $0.1 \% \mathrm{ZnO}$ films as well as a significant twinning during annealing, but films containing higher concentrations of $\mathrm{ZnO}$ showed no significant grain growth as a result of thermal cycling. Multiple cycles of pure $\mathrm{Au}, 0.5 \% \mathrm{ZnO}$ and $2.0 \% \mathrm{ZnO}$ show stable microstructures for pure $\mathrm{Au}$ and $2.0 \%$, with no additional grain growth. However, the $0.5 \% \mathrm{ZnO}$ continues to show additional grain growth which suggests the concentration threshold to stop grain growth is somewhere between $0.5 \%$ and $2.0 \% \mathrm{ZnO}$. Nanoindentation experiments conducted on as deposited and annealed films show increasing hardness with $\mathrm{ZnO}$ concentration, while the drop in hardness observed following annealing can be attributed to grain growth. Four- 
point probe resistivity measurements showed increasing resistivity as $\mathrm{ZnO}$ concentration increases for as-deposited films, as is expected through traditional models. Annealed films showed a significant drop in resistivity, which is attributed to a change in the particle-matrix interface structure.

A model that consistently describes both the experimental hardness and sheet resistance has been developed based on the assumption that the impact of nm-scale $\mathrm{ZnO}$ precipitates on the mechanical and electrical behavior of Au films is most likely dominated by a transition from semi-coherent to incoherent interfaces. The presence of $\mathrm{ZnO}$ and/or excess $\mathrm{Zn}$ in solid solution at grain boundaries refines the grain size during growth as well as limits grain growth during annealing. The final result in the two-phase films is that dilute additions of $\mathrm{ZnO}$ to Au produce electrical contact surfaces that are more microstructurally stable and mechanically robust than pure gold while only moderately increasing the resistivity over pure gold. These results are similar to other ODS-gold systems, and suggest that the impact of nm-scale oxide particles in gold on hardness and resistivity is relatively independent of the oxide chemistry, suggesting there are likely other ODS systems which may provide similar behavior.

\section{Acknowledgements}

Assistance from Drs. Megan Cordill and Daniel Kiener at the Erich Schmitt Institute in Leoben, Austria with wafer curvature testing is greatly appreciated. Sandia National Laboratories is a multi-program laboratory managed and operated by Sandia Corporation, a wholly owned subsidiary of Lockheed Martin Corporation, for the U.S. Department of Energy's National Nuclear Security Administration under contract DE-AC04-94AL85000. 


\section{References}

[1] Kim B-N, Hiraga K, Sakka Y, Ahn B-W. Acta Mater 1999;47:3433.

[2] Kirchheim R. Acta Mater 2002;50:413.

[3] Ghosh AK, Hamilton CH. Metall Trans A 1979;10:699.

[4] Senkov ON, Myshlyaev MM. Acta Metall 1986;34:97.

[5] Gianola DS, Van Petegem S, Legros M, Brandstetter S, Van Swygenhoven H, Hemker KJ. Acta Mater 2006;54:2253.

[6] Hyman D, Mehregany M. IEEE Trans Components Packag Technol 1999;22:357.

[7] Leedy KD, Cortez R, Ebel JL, Strawser RE, Walker a. P, DeSalvo GC, Young RM. J Vac Sci Technol A Vacuum, Surfaces, Film 2003;21:1172.

[8] Song J, Srolovitz DJ. Acta Mater 2007;55:4759.

[9] Dickrell DJ, Dugger MT. The Effects of Surface Contamination on Resistance Degradation of Hot-Switched Low-Force MEMS Electrical Contacts, in:. Proc. Fifty-First IEEE Holm Conf. On. IEEE. 2005.

[10] Dickrell DJ, Dugger MT. IEEE Trans Components Packag Technol 2007;30:75.

[11] Chew YH, Wong CC, Wulff F, Lim FC, Goh HM. Thin Solid Films 2008;516:5376.

[12] Petch NJ. J Iron Steel Inst 1953:25.

[13] Lo CC. J Appl Phys 1979;50:6887.

[14] Hall EO. Proc Phys Soc B 1951;747.

[15] Muñoz-Morris MA, Garcia Oca C, Morris DG. Acta Mater 2002;50:2825.

[16] Millett PC, Selvam RP, Saxena A. Acta Mater 2007;55:2329.

[17] Millett PC, Selvam RP, Saxena A. Acta Mater 2006;54:297.

[18] Jankowski AF, Ahmed HST. Mater Lett 2012;77:103.

[19] Coll M, Hacker CA, Miller LH, Hines DR, Williams ED, Richter CA. ECS Trans 2009;16:139.

[20] Ghosh SK, Limaye PK, Swain BP, Soni NL, Agrawal RG, Dusane RO, Grover AK. Surf Coatings Technol 2007;201:4609. 
[21] Bannuru T, Brown WL, Narksitipan S, Vinci RP. J Appl Phys 2008;103:083522.

[22] Fuschillo N, Gimpl ML. J Mater Sci 1970;5:1078.

[23] Haslam AJ, Moldovan D, Yamakov V, Wolf D, Phillpot SR, Gleiter H. Acta Mater 2003;51:2097.

[24] Sansoz F, Dupont V. Appl Phys Lett 2006;89:111901.

[25] Zepeda-Ruiz LA, Gilmer GH, Sadigh B, Caro A, Oppelstrup T, Hamza A V. Appl Phys Lett 2005;87:231904.

[26] Weissmuller J, Krauss W, Haubold T, Birringer R, Gleiter H. Nanostructured Mater 1992;1:439.

[27] Gianola DS, Mendis BG, Cheng XM, Hemker KJ. Mater Sci Eng A 2008;483-484:637.

[28] Coutu RA, Kladitis PE, Leedy KD, Crane RL. J Micromechanics Microengineering 2004;14:1157.

[29] Jax P, Kratochvil P, Haasen P. Acta Metall 1970;18.

[30] Meyers MA, Chawla KK. Mechanical Metallurgy: Principles and Applications. 1984.

[31] Hertzberg RW. Deformation and Fracture Mechanics of Engineering Materials. 1996.

[32] Kasap SO. Priciples of Electronic Materials and Devices. 2006.

[33] Hicks WM. Nature 1930:954.

[34] Schoeppner RL, Jin H, Goeke RS, Moody NR, Bahr DF, Prasad S V. J Mater Sci 2014.

[35] Argibay N, Goeke RS, Dugger MT, Rodriguez MA, Michael JR, Prasad S V. J Appl Phys 2013;113:143712.

[36] Algahtani F, Thulasiram KB, Nasir NM, Holland AS. Proc SPIE 2013;8923:89235D.

[37] Flinn PA. Mat Res Soc Symp Proc 1989;130:41.

[38] Volkert CA, Alofs CF, Liefting JR. J Mater Res 1994;9:1147.

[39] Pedersen TPL, Kalb J, Njoroge WK, Wamwangi D, Wuttig M, Spaepen F. Appl Phys Lett 2001;79:198.

[40] Ashby MF. Acta Metall 1972;20:887.

[41] Langdon TG, Mohamed FA. Mater Sci Eng A 1978;32:103.

[42] Heinz L, White RA, Sherby OD. Mater Sci Eng A 1979;39:211.

[43] Chen M, Ma E, Hemker K, Sheng H, Wang Y, Cheng X. Science (80- ) 2003;300:1275. 
[44] Dehm G, Oh SH, Gruber P, Legros M, Fischer FD. Acta Mater 2007;55:6659.

[45] Ansell GS. Acta Metall 1961;9:518.

[46] Emery RD, Povirk GL. Acta Mater 2003;51:2079.

[47] Emery RD, Povirk GL. Acta Mater 2003;51:2067.

[48] Argibay N, Prasad SV, Goeke RS, Dugger MT, Michael JR. Wear 2013;302:955.

[49] Smits FM. Bell Syst Tech J 1958:711.

[50] Burnett AF. J Vac Sci Technol A Vacuum, Surfaces, Film 1993;11:2970.

[51] Thornton JA, Hoffman DW. J Vac Sci Technol A Vacuum, Surfaces, Film 1977;14:164.

[52] Mayadas AF, Shatzkes M. Phys Rev B 1970;1:1382.

[53] Andrews P V., West MB, Robeson CR. Philos Mag 1969;19:887.

[54] Guinier A. Nature 1938;142:569.

[55] Williams JR, Clarke DR. Acta Mater 2008;56:1813. 


\section{$\underline{\text { List of Figures }}$}

Figure 1. Stress-temperature profiles for $\mathrm{Au}-\mathrm{ZnO}$ films obtained using wafer curvature technique. (a) Single cycle profiles on as deposited films of Pure Au (red), 0.1\% $\mathrm{ZnO}$ (orange), $0.5 \% \mathrm{ZnO}$ (green), $1.0 \% \mathrm{ZnO}$ (blue), and $2.0 \% \mathrm{ZnO}$ (black). Portions of the curves corresponding to values referred to in Table 1 are labeled. (b) Additional cycles conducted on pure $\mathrm{Au}, 0.5 \% \mathrm{ZnO}$, and $2.0 \% \mathrm{ZnO}$ samples to determine microstructural stability.

Figure 2. EBSD texture map of as-deposited (a) pure $\mathrm{Au}$, (b) $0.1 \% \mathrm{ZnO}$, (c) $0.5 \% \mathrm{Zno}$, (d) 1.0\% $\mathrm{ZnO}$, and (e) $2.0 \% \mathrm{ZnO}$ and annealed (f) pure $\mathrm{Au}$, (g) $0.1 \% \mathrm{ZnO}$, (h) $0.5 \% \mathrm{ZnO}$, (i) 1.0\% $\mathrm{ZnO}$, and (j) $2.0 \% \mathrm{ZnO}$. Microstructures of films with higher concentrations of $\mathrm{ZnO}$ are significantly more stable than the lower concentration films.

Figure 3. Evolution of grain size distribution of pure $\mathrm{Au}$ (top), $0.5 \% \mathrm{ZnO}$ (middle), and 2.0\% $\mathrm{ZnO}$ films (bottom) as a result of one (dashed line) and five (dotted line) thermal cycles showing significant grain growth in pure Au sample and a stable grain size in 2.0\% ZnO sample, with accompanying EBSD scans (right).

Figure 4. Nanoindentation hardness of as deposited (solid circles) and after annealing at $350^{\circ} \mathrm{C}$ (open circles) films. Pure $\mathrm{Au}, 0.5 \% \mathrm{ZnO}$ and $2.0 \% \mathrm{ZnO}$ were cycled 5 times while the other concentrations only underwent one thermal cycle. 
Figure 5. Comparison of experimental and predicted hardness of as-deposited (a) and annealed (b) films based on the model presented in Equation 9-2, with specific contributions separated into intrinsic $\left(\sigma_{0}\right)$, grain-boundary (Hall-Petch), and precipitation (Ashby-Orowan) strength components.

Figure 6. Calculated resistivity based on four-point probe measurements of as-deposited (solid circles) and annealed (open circles) films. Samples with higher concentrations of $\mathrm{ZnO}$ particles show a reduction in resistivity after annealing at $350{ }^{\circ} \mathrm{C}$.

Figure 7. Comparison of experimental and predicted resistivity of as-deposited (a) and annealed (b) films based on the model suggested in Equation 4, with specific contributions from thermal vibrations, grain-boundary scattering, internal stresses created during annealing $\left(\sigma_{\mathrm{ann}}\right)$, and precipitate interactions.

Figure 8. Summary of the relative change in mechanical and electrical properties for the different concentrations of $\mathrm{ZnO}$ present in the films as a result of the annealing conditions investigated in this study. Higher concentration films show a minimal change in strength corresponding to a reduction in resistivity as a result of these annealing conditions. 

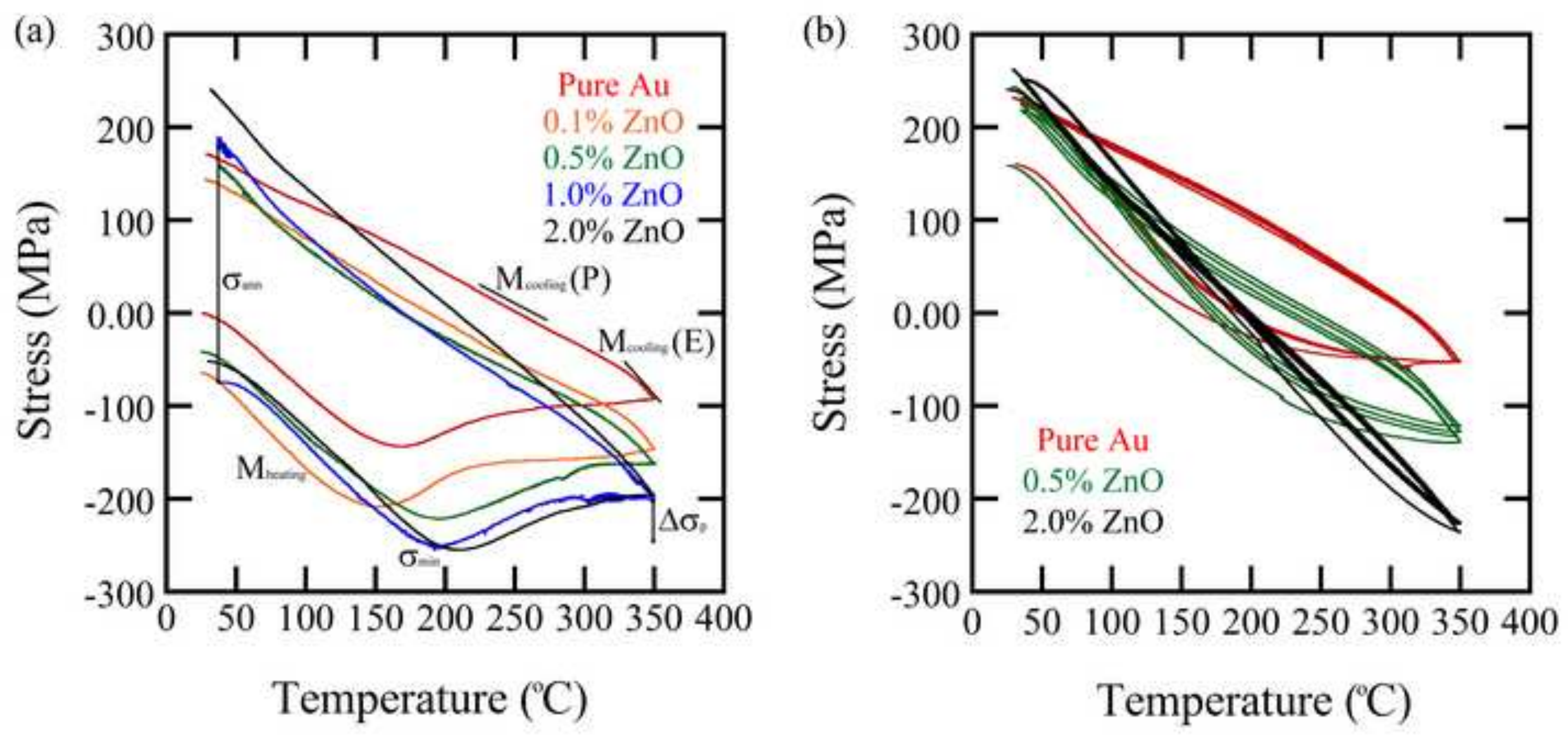


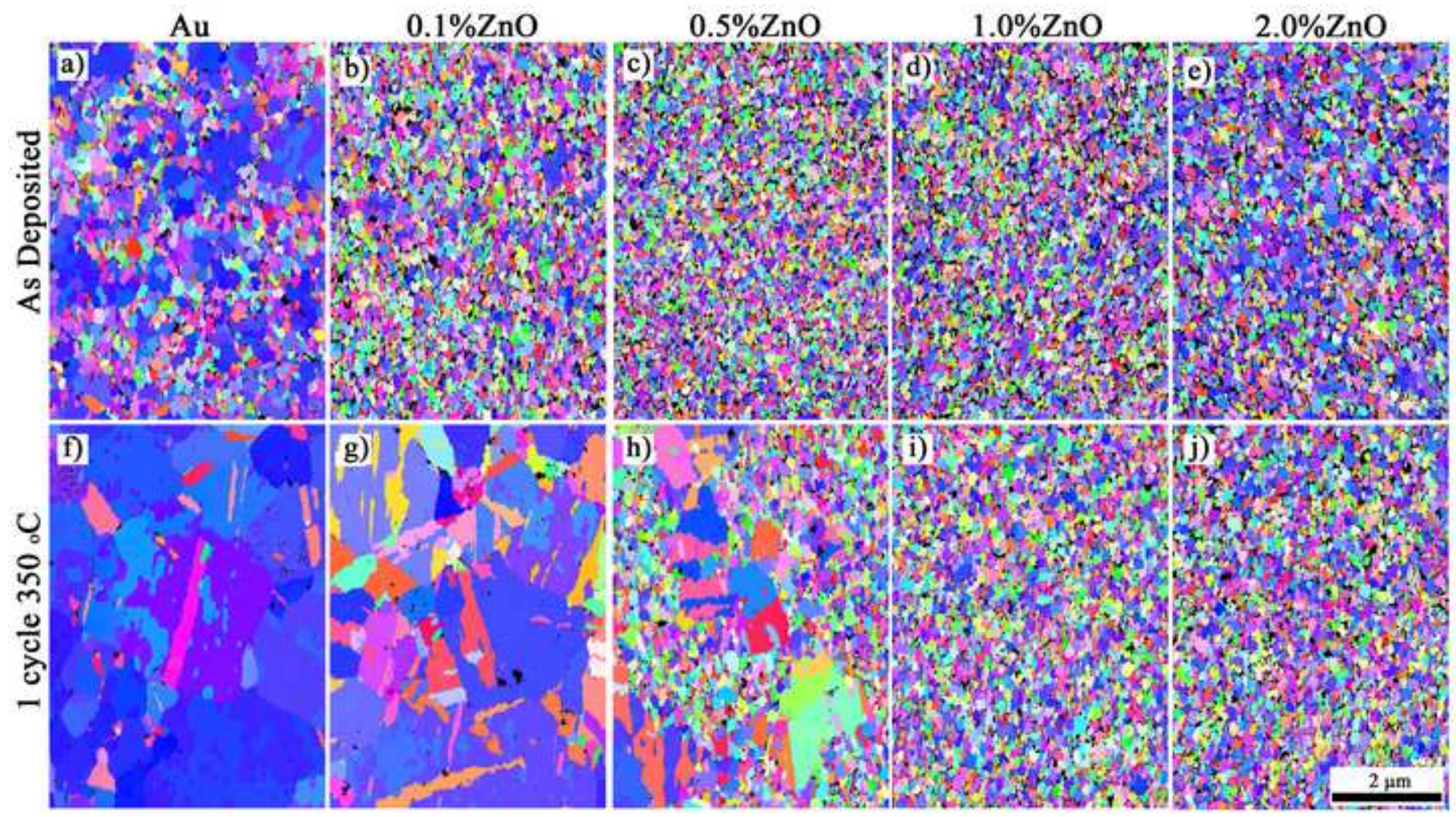


As Deposited
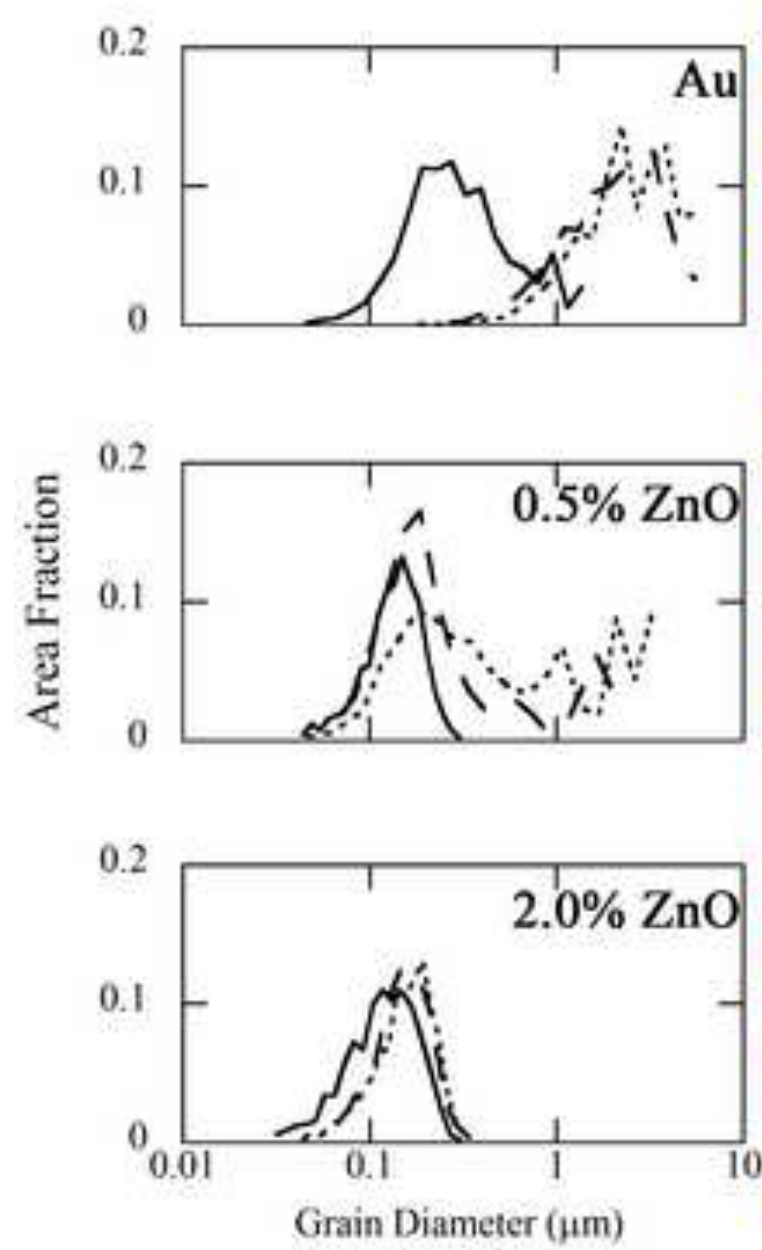

$350^{\circ} \mathrm{C} 1$ cycle
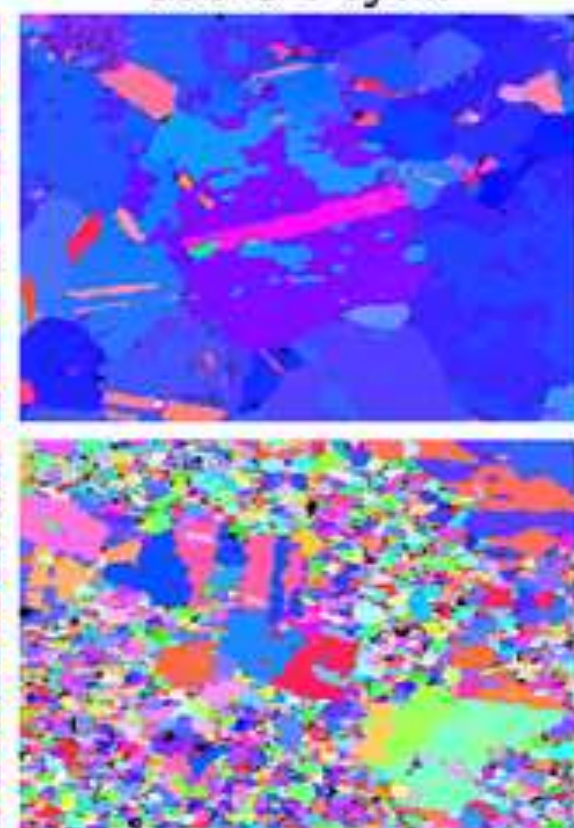

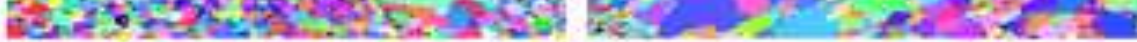

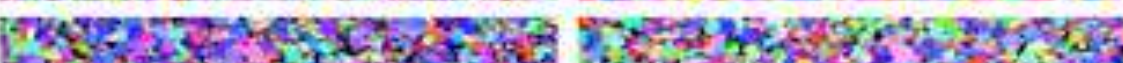
Y.

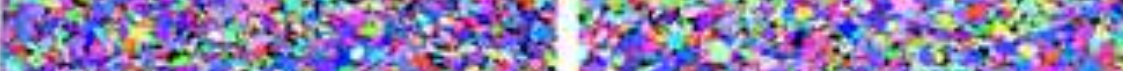

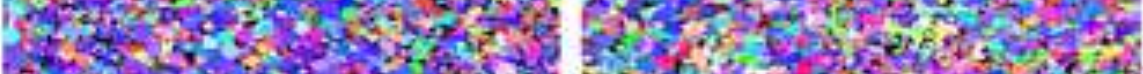

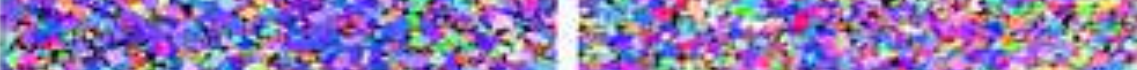

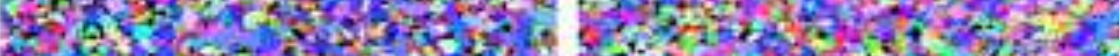

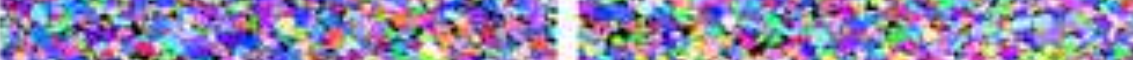

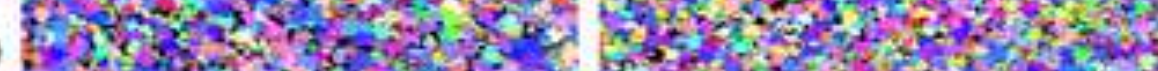

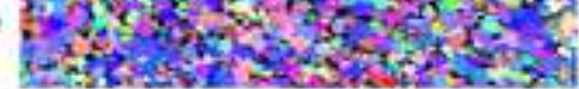

$350^{\circ} \mathrm{C} 5$ cycles
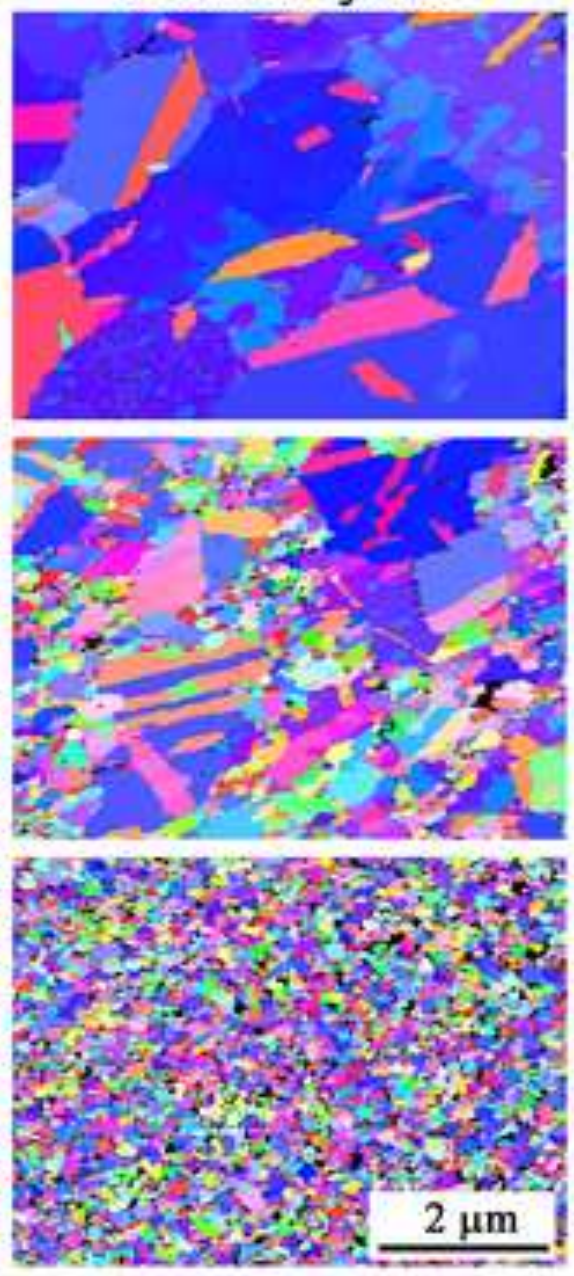


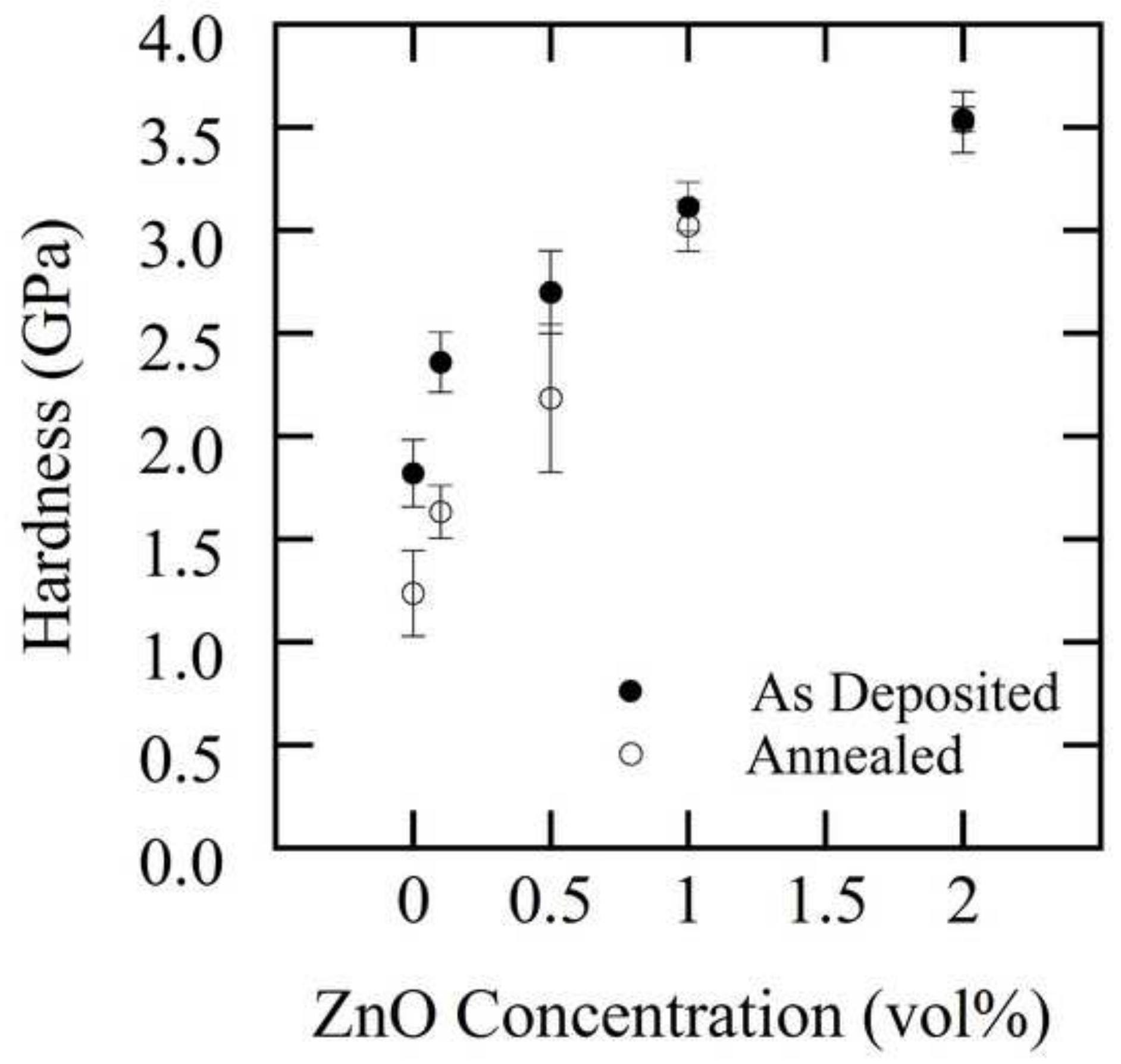




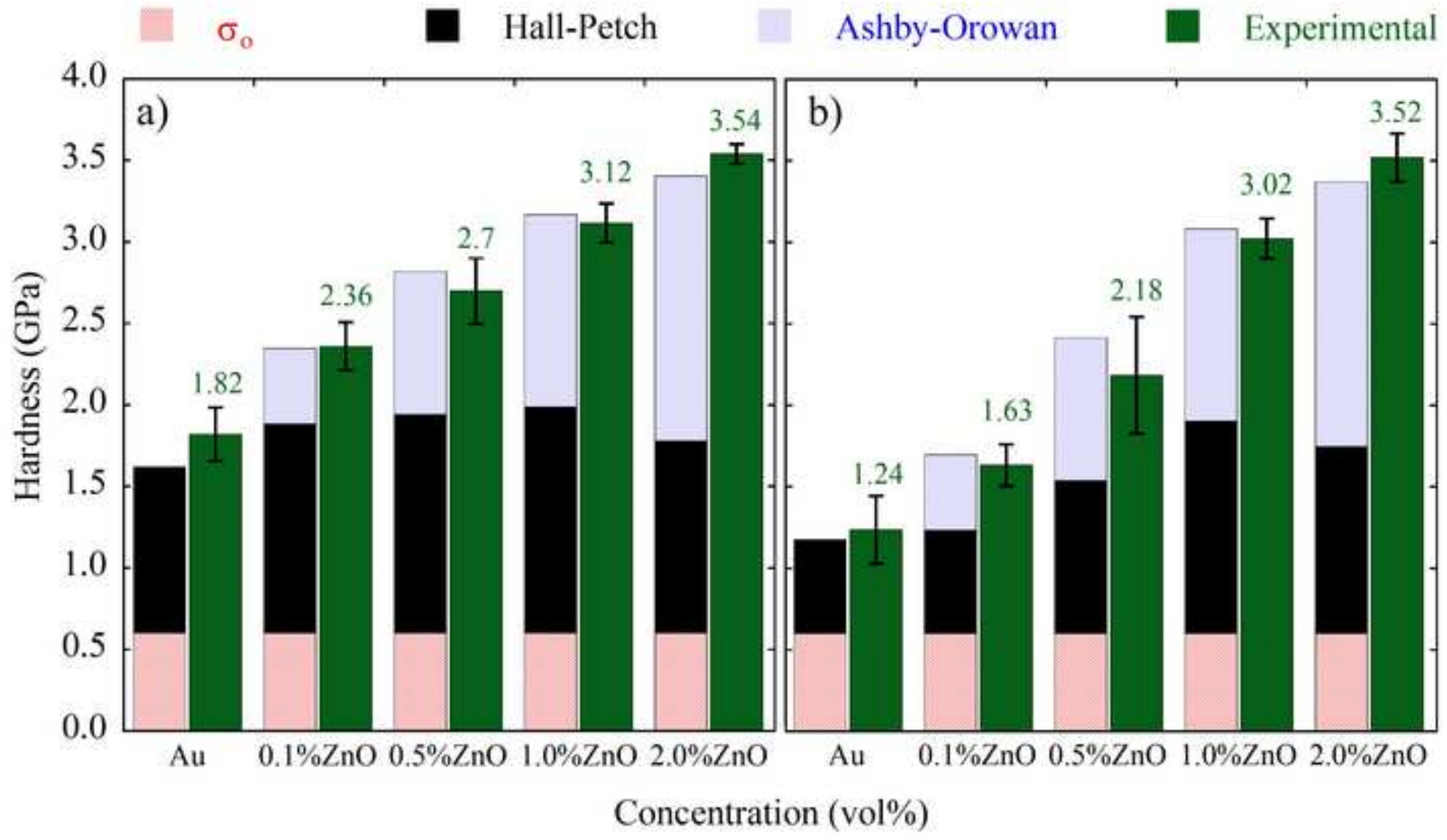




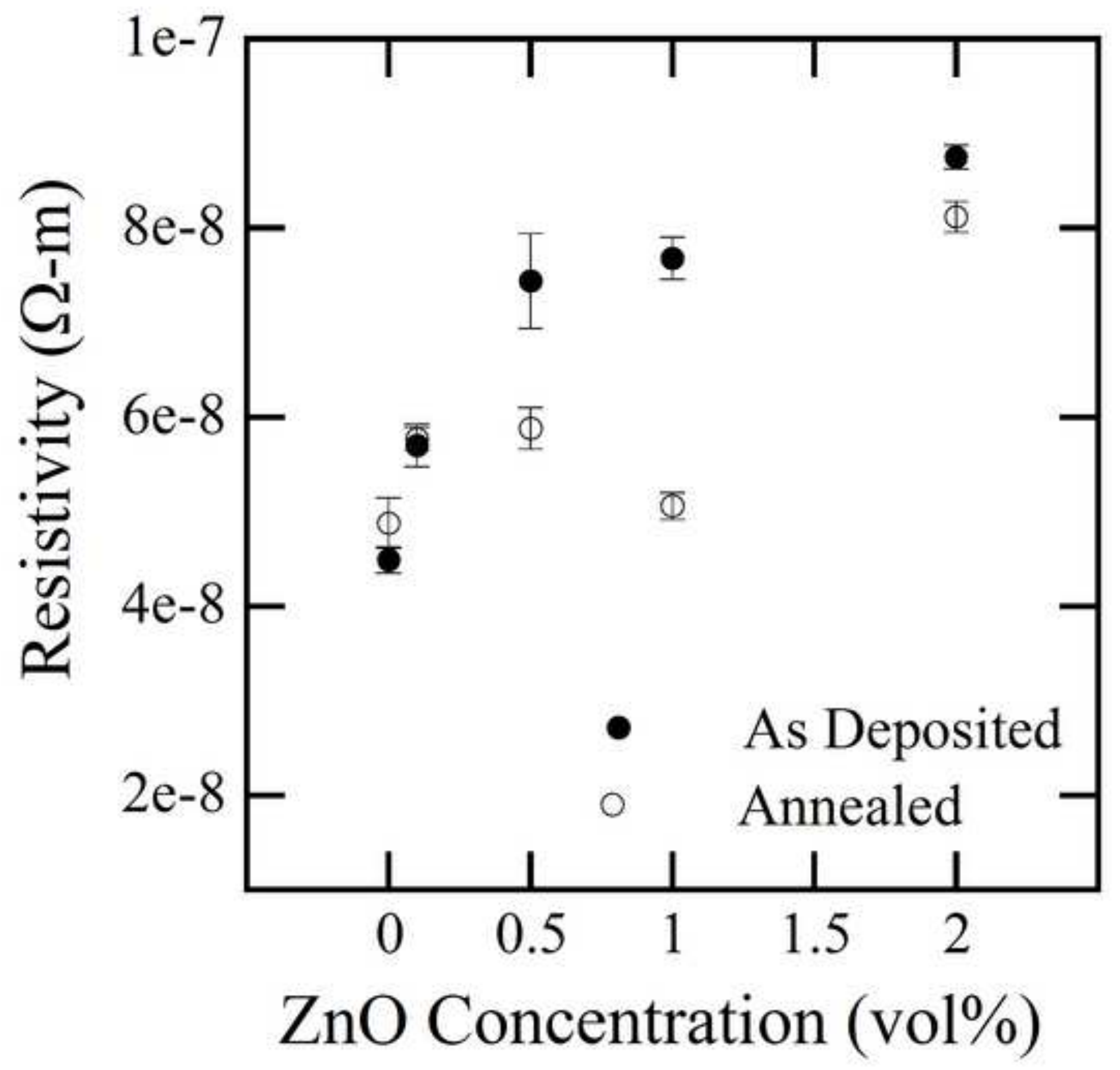




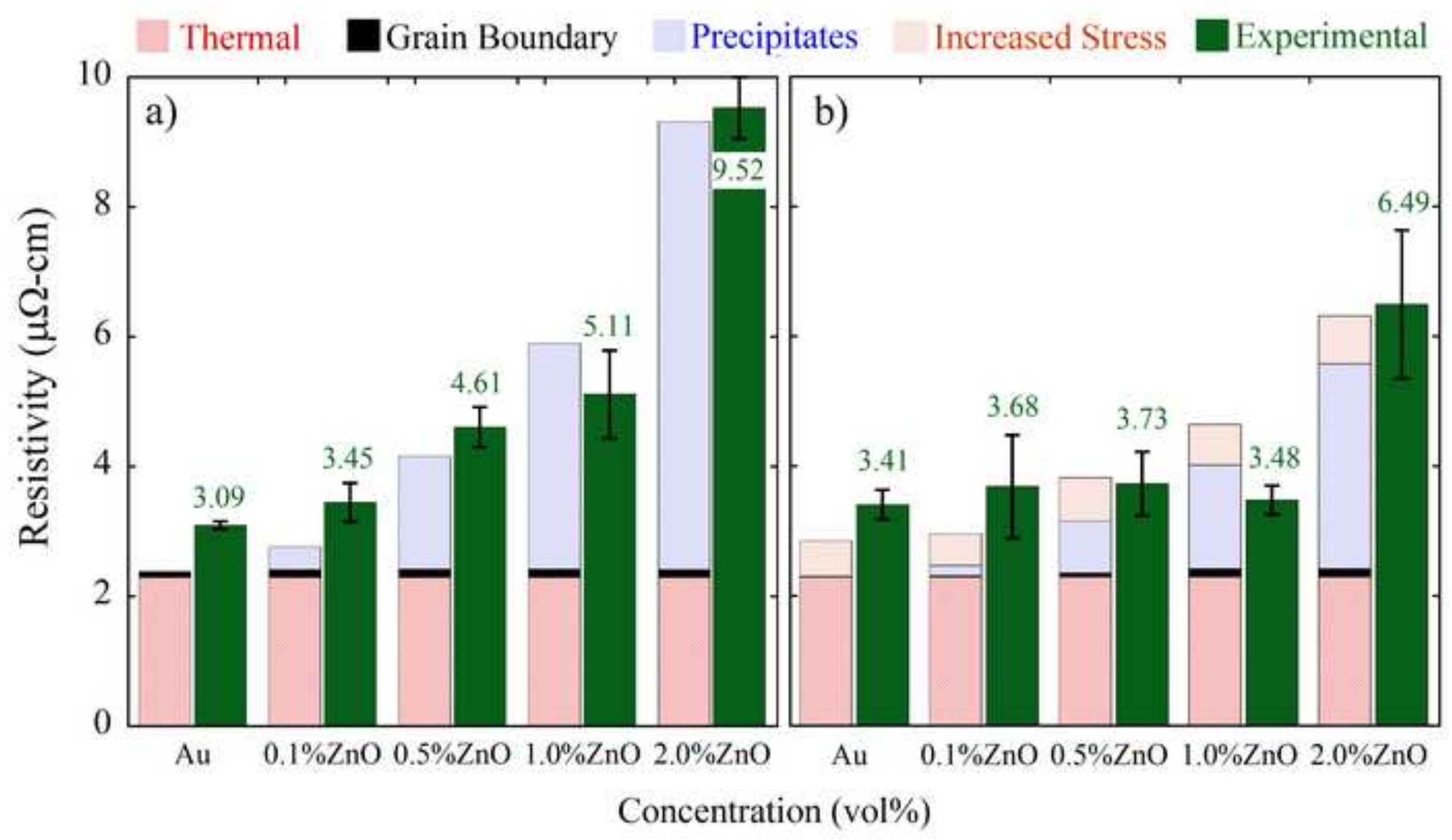




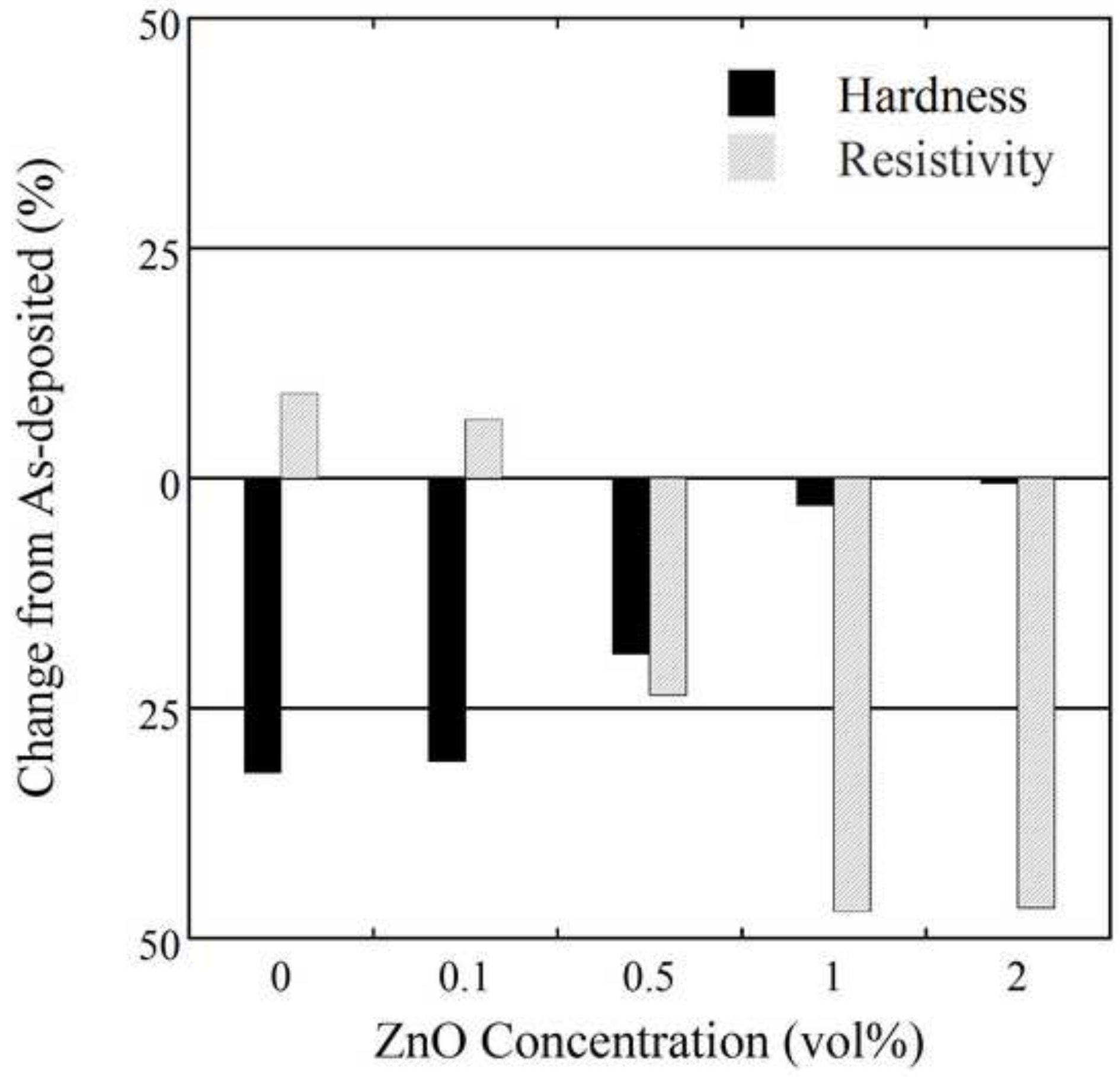




\section{Tables}

Table 1. Residual stress (MPa) in films from deposition, calculated from XRD lattice strain measurements.

\begin{tabular}{c|ccccc}
\hline & Pure $\mathrm{Au}$ & $0.1 \% \mathrm{ZnO}$ & $0.5 \% \mathrm{ZnO}$ & $1.0 \% \mathrm{ZnO}$ & $2.0 \% \mathrm{ZnO}$ \\
\hline $\begin{array}{c}\text { Residual } \\
\text { Stress (MPa) }\end{array}$ & 0 & 64.0 & 41.1 & 51.4 & 45.8 \\
\hline
\end{tabular}

Table 2. Summary of wafer curvature results for all film concentrations

\begin{tabular}{c|ccccc}
\hline & $\mathbf{A u}$ & $\mathbf{0 . 1 \% Z n O}$ & $\mathbf{0 . 5 \% Z n O}$ & $\mathbf{1 . 0 \% Z n O}$ & $\mathbf{2 . 0 \% Z n O}$ \\
\hline Maximum & 171.02 & 143.65 & 159.80 & 189.76 & 240.61 \\
Minimum & -143.79 & -209.04 & -221.55 & -255.08 & -255.31 \\
$\boldsymbol{\sigma}$ at $\mathbf{3 5 0} \mathbf{C}$ & -92.54 & -146.14 & -161.75 & -199.59 & -196.08 \\
$\boldsymbol{\Delta \sigma}_{\mathbf{p}}$ & -51.25 & -62.90 & -59.80 & -55.49 & -59.22 \\
$\mathbf{M}_{\text {heating }}$ & -1.27 & -1.55 & -1.43 & -1.37 & -1.30 \\
$\mathbf{M}_{\text {cooling }}(\mathbf{E})$ & -1.74 & -1.98 & -1.70 & -1.80 & -1.94 \\
$\mathbf{M}_{\text {cooling }}(\mathbf{P})$ & -0.83 & -0.67 & -0.73 & $\mathbf{- 1 . 1 5}$ & $\mathbf{- 1 . 2 7}$ \\
$\boldsymbol{\Delta \sigma}_{\text {anneal }}$ & $231.82^{*}$ & 207.83 & $285.19^{\star}$ & 265.26 & $314.41^{\star}$ \\
\hline
\end{tabular}

*values calculated after 5 cycles 